Kong. Res. J. 1(2): 80-84, 2014

Kongunadu Arts and Science College, Coimbatore

\title{
SCREENING AND DETERMINATION OF ANTIOXIDANT SCAVENGING ACTIVITY OF PIPER LONGUM AND EUCALYPTUS CAMALDULENSIS
}

\author{
Kuppusamy Mohanraj and Naganathan Srinath* \\ Department of Biotechnology, Kongunadu Arts and Science College, Coimbatore. \\ *E-mail: sri7486@gmail.com
}

\begin{abstract}
The herbal medicine is used from time immemorial to treat various common ailments like cold, cough and gastric problems. India has various system of treatment like Ayurveda, Siddha, Unani and Homeopathy which are devoid of side effects and treat the person with higher benefits. Piper longum fruits and Eucalyptus camaldulensis Dehnh., leaves has been used as spices and for medicinal oil preparation for various treatment. We have made an attempt to elevate the importance of these herbal sources by understanding the antioxidant scavenging activity. We have extracted and processed the plants fruit and leaves using different solvents in 1:10 dilution such as petroleum ether, chloroform ethanol, hexane, methanol and distilled water. It was found that ethanol and methanol extract of Piper longum and Eucalyptus camaldulensis Dehnh., has higher antioxidant activity when compared with the standard Vitamin $\mathrm{C}$ and $\mathrm{IC}_{50}$ value was observed to be nearly $70 \mu \mathrm{g} / \mathrm{ml}$ for all the tests.
\end{abstract}

Key words: Piper longum, Eucalyptus camaldulensis Dehnh., DPPH', ABTS+, FRAP.

\section{INTRODUCTION}

Cold and cough is always considered as drastic problem which everyone suffers in all parts of world. India a reservoir for various herbs uses plants and their products to treat the common problems time immemorial. The World Health Organization (WHO) has found that out off 3000 plants most of them are available in India and the usages of these plants are nearly by $80 \%$ of the world population (WHO report, 2009). With an increase rate of over exposure towards various antibiotics has created an environment of multidrug resistance microbes such as Escherichia coli, Klebsiella pneumoniae, Aeromonas sp., Mycobacterium tuberculosis, M. leprae, Candida sp., etc. (Waters and Basseler, 2005). This has made the scientists to explore new drugs either using plant sources like medicinal herbs or their parts or chemical sources. Due to the concern related to the side effects by the usages of chemical drugs (Hassan, 2012) made a shift in the path of drug usages and caused the public to use herbal medicinal sources for the treatment like Ayurveda, Siddha, Unani and Homeopathy.

In the current research we have chosen Piper longum fruits and Eucalyptus camaldulensis Dehnh., leaves as the source with medicinal property for treating the common problem of cold and cough. Piper longum belongs to the Piperaceae family and is thought to originate from South East Asia and Eucalyptus sp. commonly found in the dry and hilly areas are having many medicinal roles in Ayurveda and in modern medicine. Before evaluating any medicinal plant, it is essential to understand its antioxidant potential because there are various free radicals released by our body and by various products intake (Abrahim et al., 1993; Gupta and Ray, 2004; Kumar et al., 2010; Arawwala et al., 2011). It has also been found that these free radicals remain as an adjuvant in causing cancer like breast cancer. These plants are used commonly as spices or for inhalation treatment for curing the common ailment and it is essential to evaluate the antioxidant potential of these drugs as when used and inhaled could sometime reach the blood stream either by absorption from the tissues or from the stomach (Manoj et al., 2004; Sadlon et al., 2010; Chahal et al., 2011). We have aimed to understand the scavenging potential of these plants as they are commonly used in India as a source for treating common cold and cough problems in various parts of India.

\section{MATERIALS AND METHODS}

\subsection{Collection of herbal plants}

Piper longam fruits and E. camaldulensis Dehnh., leaves were collected from in and around Coimbatore and subjected for plant authentication at Botanical Survey of India, Coimbatore, Tamil Nadu.

\subsection{Processing of Plant fruits and leaves using cold percolation method}

The plant leaves and stems were processed using cold percolation method as described by Adonizio et al. (2008). The cold percolation method helps to retain the medicinal property of any 
medicinal plant. The plant leaves and fruits were stored in dark for a period of 2-3 weeks and were powdered. The powders of plant leaves and fruits were sieved and stored in dark bottle. The powdered plant leaves and fruits were weighed and mixed with different solvents in 1:10 dilution in increasing order of polarity such as petroleum ether, chloroform ethanol, hexane, methanol and distilled water.

They were shaken well during the process to avoid fungal contamination and filtered using muslin cloth. The filtrate was kept in watch glass in dark for evaporation and scrapped powders were stored in dark bottle as they are light sensitive. The extracts were subjected to antioxidant scavenging activity and subjected for future research against pathogens.

2.3. Evaluating the various antioxidant properties of extracted Piper longum and Eucalyptus camaldulensis Dehnh. by in vitro free radical scavenging activity

\subsubsection{DPPH scavenging activity}

The 2,2-diphenyl-1picryl hydrazyl (DPPH') scavenging activity of $P$. longum and E. camaldulensis Dehnh. is performed using the method described by Blois, in 1995. DPPH $^{\circ}$ is scavenged by antioxidants through the donation of a proton forming the reduced DPPH: Various concentrations of samples were taken along with Vitamin $\mathrm{C}$ as standard in different test tubes. The volume was adjusted to 500 $\mu \mathrm{L}$ by adding methanol and $5 \mathrm{~mL}$ of $0.1 \mathrm{mM}$ methanolic solution of DPPH was added to these test tubes and vortexed. The tubes were allowed to stand at room temperature for $20 \mathrm{~min}$. The control was prepared as above without any extract and methanol was used for the baseline correction. The color change from purple to yellow after reduction can be quantified by its decrease in absorbance at wavelength $517 \mathrm{~nm}$. The percentage of inhibition radical scavenging activity was measured by the formula:

\section{Percentage of radical scavenging activity $=\frac{\text { Control }- \text { Sample }}{\text { Control }} 100$ Control value}

The percentage inhibition vs. concentration was plotted and the concentration required for $50 \%$ inhibition of radicals was expressed as $\mathrm{IC}_{50}$ value.

\subsection{2. $\mathrm{ABTS}^{+}+$radical scavenging activity}

The test was based on the relative activity of antioxidants to quench the radical cation ABTS $\left(2,2^{\prime}-\right.$ azino-bis(3-ethylbenzothiazoline-6-sulphonic acid)+ was done using the method described by $\operatorname{Re}$ et al. (1999). $\mathrm{ABTS}^{\circ}+$ decolorisation assay involves the generation of the $\mathrm{ABTS}^{\circ}{ }^{+}$chromophore by the oxidation of $\mathrm{ABTS}^{*}+$ with ammonium per sulphate. It is applicable for both hydrophilic and lipophilic compounds. The reaction was initiated by the addition of $1.0 \mathrm{~mL}$ of diluted ABTS to $10 \mu \mathrm{L}$ of different concentration of extract with high antibiofilm activity of the sample or $10 \mu \mathrm{L}$ of methanol serve as control. The absorbance was read at $734 \mathrm{~nm}$. Percentage inhibition was calculated by the formula

$$
\text { Percentage of radical scavenging activity }=\frac{\text { Control }- \text { Sample }}{\text { Control value }} \times 100
$$

\subsubsection{Hydrogen Peroxide scavenging activity}

The hydrogen peroxide scavenging activity was measured in terms of a decrease in the absorbance as $230 \mathrm{~nm}$ in spectrophotometer using the method described by Ruch et al. (1989). A solution of $\mathrm{H}_{2} \mathrm{O}_{2}$ was prepared in phosphate buffer and the $\mathrm{H}_{2} \mathrm{O}_{2}$ concentration was determined using spectrophotometer at $230 \mathrm{~nm}$ wavelength. Various concentrations of plant extracts were added to $\mathrm{H}_{2} \mathrm{O}_{2}$ and incubated for $10 \mathrm{~min}$. The absorbance at $230 \mathrm{~nm}$ was determined against a blank containing phosphate buffer without $\mathrm{H}_{2} \mathrm{O}_{2}$. The percentage of scavenging of $\mathrm{H}_{2} \mathrm{O}_{2}$ and standard compound Vitamin $\mathrm{C}$ was calculated using the formula:

$$
\text { Percentage of radicalscavengingactivity }=\frac{\text { Control }- \text { Sample }}{\text { Control value }} \times 100
$$

\subsubsection{Hydroxyl radical scavenging activity}

Hydroxyl radicals were generated from ferrous ammonium sulphate and EDTA were determined against the scavenging activity of the plant extracts using the method described by Klein et al. (1991). Various concentration of plant extracts were added with $1 \mathrm{~mL}$ of iron-EDTA solution $(0.13 \%$ ferrous ammonium sulphate and $0.26 \%$ EDTA), 0.5 $\mathrm{ml}$ of EDTA solution (0.018\%), and $1 \mathrm{~mL}$ of DMSO $(0.85 \% \mathrm{v} / \mathrm{v}$ in $0.1 \mathrm{M}$ phosphate buffer, $\mathrm{pH}$ 7.4). The reaction was initiated by adding $0.5 \mathrm{ml}$ of ascorbic acid $(0.22 \%)$ and incubated at 80 to $90{ }^{\circ} \mathrm{C}$ for $15 \mathrm{~min}$ in a water bath. After incubation the reaction was terminated by the addition of $1 \mathrm{~mL}$ of ice-cold trichloro acetic acid (TCA) (17.5\% w/v). About $3 \mathrm{~mL}$ of Nash reagent $(75 \mathrm{~g}$ of ammonium sulphate, $3 \mathrm{ml}$ of glacial acetic acid and $2 \mathrm{~mL}$ of acetyl acetone were mixed and make up to $1 \mathrm{~L}$ with distilled water) was added and left at room temperature for $15 \mathrm{~min}$. The reaction mixture without sample was used as control. This was detected by their ability to react with ascorbic acid to produce yellow color complex which was measured at $412 \mathrm{~nm}$ against reagent 
blank. The percentage of hydroxyl radical scavenging activity is calculated by the following formula

$$
\text { Percentage of radical scavenging activity }=\frac{\text { Control }- \text { Sample }}{\text { Control value }} \times 100
$$

\subsubsection{Ferric reducing antioxidant power (FRAP) assay}

The total antioxidant potential of sample was determined using ferric reducing antioxidant power (FRAP) using the method described by Benzie and Strain, 1996. The stock solution of $10 \mathrm{mM} \mathrm{2,} \mathrm{4,} \mathrm{6-}$ tripyridyl-s-triazine (TPTZ) in $40 \mathrm{mM} \mathrm{HCl}, 20 \mathrm{~mm}$ $\mathrm{FeCl}_{3}, 6 \mathrm{H}_{2} \mathrm{O}$ and $0.3 \mathrm{M}$ acetate buffer $(\mathrm{pH} 3.6)$ were prepared. The FRAP reagent contained $2.5 \mathrm{~mL}$ TPTZ solution, $2.5 \mathrm{~mL}$ ferric chloride solution and $25 \mathrm{~mL}$ acetate buffer. It was freshly prepared and warmed to $37{ }^{\circ} \mathrm{C} .900 \mu \mathrm{L}$ FRAP reagent were mixed with 90 $\mu \mathrm{L}$ water and $30 \mu \mathrm{L}$ test sample/ethanol/distilled water/standard antioxidant solution. The reaction mixture was then incubated at $37^{\circ} \mathrm{C}$ for $30 \mathrm{~min}$ and the absorbance was recorded at $595 \mathrm{~nm}$. An intense blue color complex were formed when ferric tripyridyl triazine $\left(\mathrm{Fe}^{3+}\right.$-TPTZ $)$ complex were reduced to ferrous $\left(\mathrm{Fe}^{2+}\right)$ form. The absorption at $540 \mathrm{~nm}$ was recorded. The calibration curve was plotted with absorbance at $595 \mathrm{~nm}$ vs concentration of ferrous sulphate in the range $0.1 \mathrm{mM}$ ethanol solutions. The concentrations of $\mathrm{FeSO}_{4}$ were in turn plotted against concentration of standard antioxidants.

$$
\text { Percentage of radical scavenging activity }=\frac{\text { Control }- \text { Sample }}{\text { Control value }} \times 100
$$

\section{RESULTS AND DISCUSSION}

The collected $P$. longum fruit and $E$. camaldulensis Dehnh., leaves were taken to Botanical Survey of India, Coimbatore and authentication no. for the plant is BSI/SRC/5/23/2013-14/Tech./2089. The processing and extraction of the plants fruit and leaves were done accordingly and the ethanolic and methanolic extract of P. longum and E. camaldulensis Dehnh. were subjected for further scavenging activity analysis based on the work done by Kumar and Laxmidhar (2011).

3.1. Evaluating the various antioxidant properties of extracted Piper longum and Eucalyptus camaldulensis Dehnh. by In vitro free radical scavenging activity

The ethanol and methanol extracts of Piper longum and Eucalyptus camaldulensis Dehnh., were carried out with antioxidant test and identified that the free radical of the extract were found to have high percentage of inhibition against $\mathrm{DPPH}^{\circ}, \mathrm{ABTS}^{*}$, hydrogen peroxide, hydroxyl and FRAP. Vitamin C served as the standard for all the antioxidant assays carried out in the study and when compared the ethanol and methanol extracts of P. longum and $E$. camaldulensis Dehnh., found to relatively higher and similar to the standard vitamin $\mathrm{C}$. The results were observed to have higher percentage of inhibition for the extracts and the $\mathrm{IC}_{50}$ value was observed as $70 \mu \mathrm{g}$ $\mathrm{mL}^{-1}$ (as shown in Fig. 1, 2, 3, 4 and 5) which was found to be similar to the results of Kumar and Laxmidhar (2011).

This shows that $P$. longum and $E$. camaldulensis Dehnh. has higher scavenging activity as compared with the previous results of Kumar and Laxmidhar (2011). Based on the experimental outcome of various researchers, the antioxidant activities, antimicrobial, antitumour and etc., of the fruit of $P$. longum showed higher activities and proved to be useful in many Ayurvedic preparations for treating various ailments (Manoj et al., 2004; Chahal et al., 2011). Antioxidant activities were measured using FRAP, DPPH', superoxide anion, nitric oxide and hyroxyl radical scavenging assays was also found to higher as the result obtained in the current research (Abrahim et al., 1993).

\section{CONCLUSION}

This proves that both the plants $P$. longum and E. camaldulensis Dehnh., have higher scavenging activity using the ethanolic and methanolic extract of plant fruits and leaves. This shows that these plant extracts can be further studied in future to understand the antibacterial activity as well as can serve as a potent drug in future pharmaceutical research for treating various common diseases and in cancer research.

\section{ACKNOWLEDGEMENT}

We acknowledge DBT-STAR College Scheme, Department of Biotechnology, New Delhi for their financial support and encouraging research in undergraduate level. We thank our management, Kongunadu Arts and Science College, for its infrastructure and laboratory support for this research work.

\section{REFERENCES}

Abraham R., K. Angel and K. Ron, (1993). Protection of the rat jejunal mucosa against oxidative injury by cationized superoxide dismutase. $J$. Pharm. Sci. 82(12):1285-1287.

Adonizio A., K. Kok-Fai and M. Kalai, (2008). Inhibition of quorum sensing-controlled virulence factor production in Pseudomonas 
aeruginosa by South Florida plant extracts.

Antimicrob Agents Chemother. 52(1):198-203.

Arawwawala, M., I. Thabrew, L. Arambewela and S. Handunnetti, (2010). Anti-inflammatory activity of Trichosanthese cucumerina Linn. in rats. J. Ethanopharmacol. 131:538-43.

Benzie, I. F. F. and J. J. Strain, (1996). Ferric reducing ability of plasma (FRAP) as a measure of antioxidant power: The FRAP assay. Anal. Biochem. 239: 70-76.

Chahal Jagbeer, Renu Ohlyan, Ajit Kandale, Anu Walia and Sidharth Puri (2011). Introduction, Phytochemistry, Traditional uses and Biological Activity of Genus Piper: A review. Int. J. Current Pharam. Rev. Res. 2(2):1-15.

Gupta, P. C., and C. S. Ray (2004). Epidemiology of betel quid usage. Ann. Acad. Med. 33(4):31-36.

Hassan Bassam Abdul Rasool (2012). Main critical side effects associated with chemotherapy used in cancer treatment. Pharm. Analytica Acta. 3(5):1000e113.

Klein S. M., G. Cohen and A. I. Cederbaum, (1991). Production of formaldehyde during metabolism of dimethyl sulphoxide by hydroxyl radical radical generating system. Biochemistry. 20: 6006-6012.

Kumar A., Garg B. R., Rajput G., Chandel D., Muwalia A., Bala I. and Singh Sumeer, (2010). Antibacterial activity and quantitative determination of protein from leaf of Datura stramonium and Piper betle plants. Pharmacophore. 1(3):184-195.

Kumar Hardel Danendra and Laxmidhar Sahoo, (2011). A review of Phytochemical and Pharmocological of Eucalyptus globules: a multipurpose tree. Int. J. Res. Ayurveda and Pharmacy. 2(5):1527-1530.

Manoj, P., E. V. Soniya, N. S. Banerjee, and P. Ravichandran, (2004). Recent studies on well known spice, Piper longum Linn. Nat. Prod. Radiance. 3(4):222-227.

Re R., N. Pelligrini, A. Proteggeenate, M. Yang and C. Rice-Evans, (1999). Antioxidants activity of applying an improved ABTS radical cation decolorisation assay. Free Radic. Biol. Med. 26: 1231-1237.

Ruch R., S. Cheng and J. Klauning, (1989). Prevention of cytoxicity and inhibition of intercellular communication antioxidant catechins isolated from Chinese green tea. Carcinogenesis. 10: 1003-1008.

Sadlon E. Angela and Lamson W. Davis, (2010). Immune-modifying and antimicrobial effects of eucalyptus oil and simple inhalation devices. Altern. Med. Rev. 15(1):33-47.

Waters, C. M. and B. L. Bassler, (2005). Quorum sensing: cell-to-cell communication in bacteria. Annu. Rev.Cell Dev. Biol. 21: 319-346.

WHO survey, (2009). In medicinal plants (Eds. Haq. I.) Hamdard Foundation Press, Karachi, 13.

Fig. 1. DPPH ${ }^{\bullet}$ radical scavenging activity of $P$. longum and E. camaldulensis Dehnh.

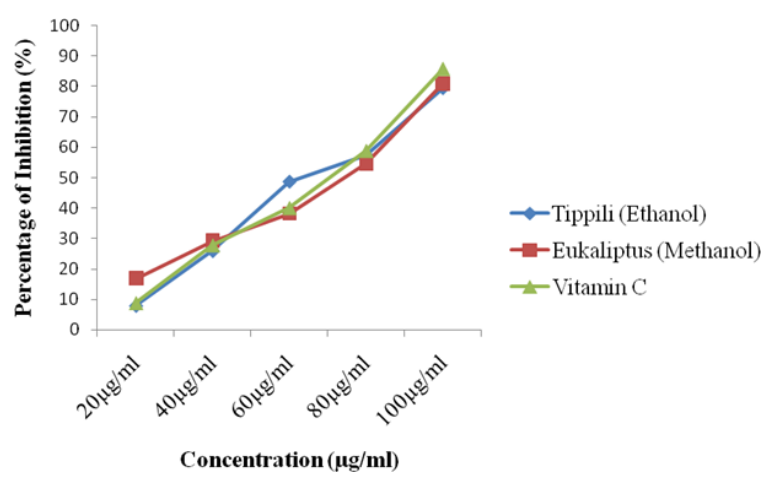

Fig. 2. ABTS ${ }^{+}$radical scavenging activity of $P$. longum and E. camaldulensis Dehnh.

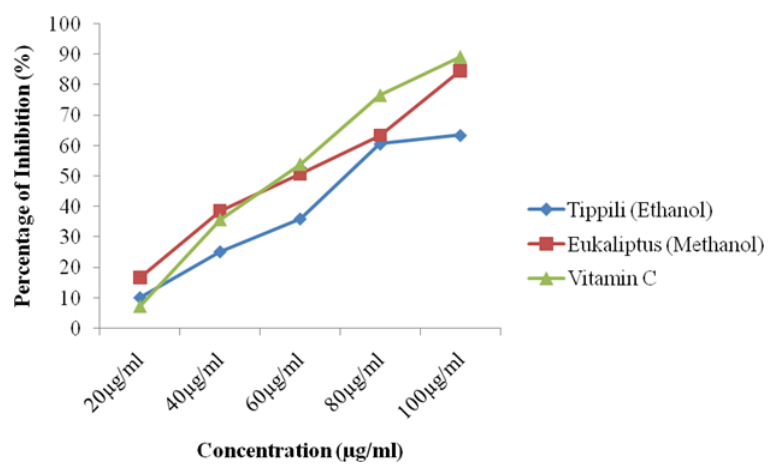


Fig. 3. Hydroxyl radical scavenging activity of $P$. longum and E. camaldulensis Dehnh.

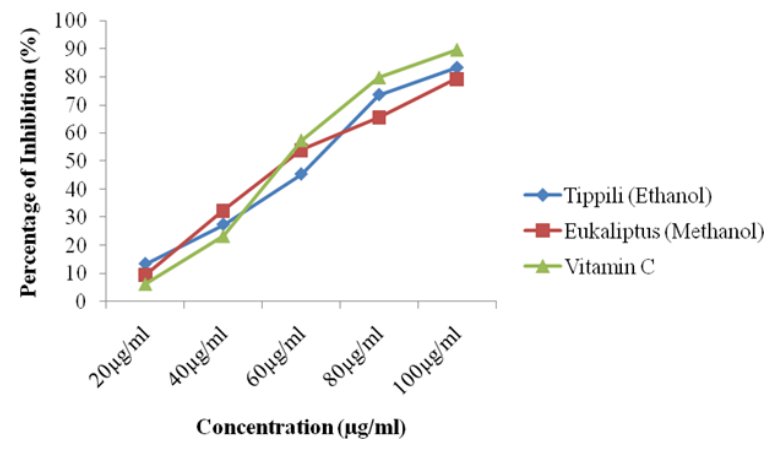

Fig. 4. Hydrogen Peroxide radical scavenging activity of $P$. longum and $E$. camaldulensis Dehnh.

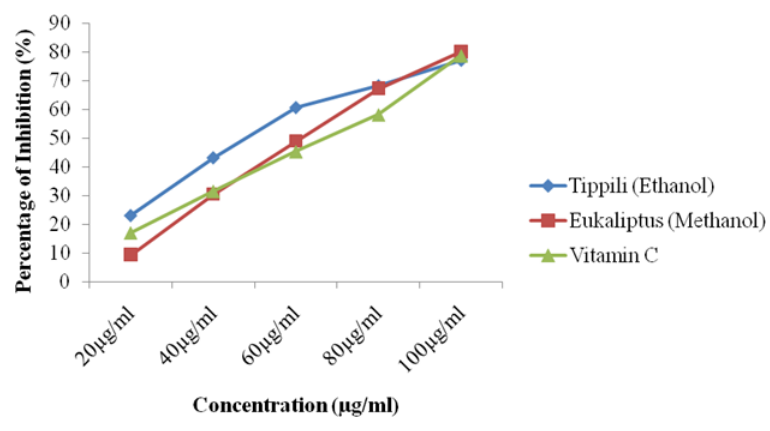

Fig. 5. FRAP radical scavenging activity of $P$. longum and $E$. camaldulensis Dehnh.

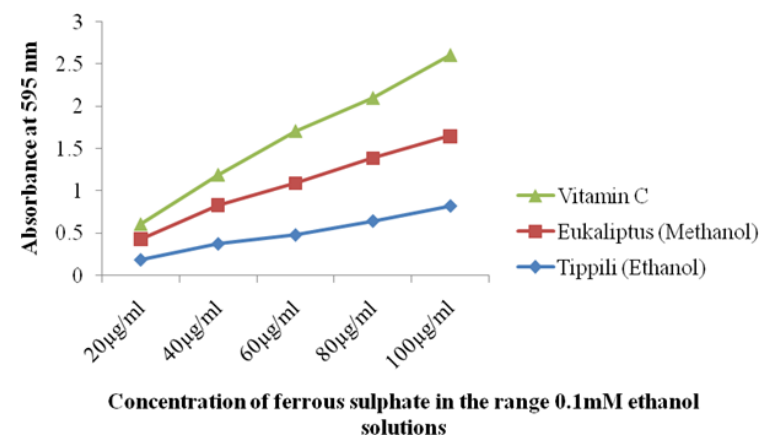

